\title{
Analisis Faktor Risiko Kejadian Malaria di Wilayah Kerja Puskesmas Kuala Bhee Kecamatan Woyla Kabupaten Aceh Barat
}

\author{
Analysis of Risk Factors of Malaria incidence in the Working Area of Kuala Bhee Public \\ Health Center in Woyla District, West Aceh
}

\author{
Hasrah Junaidi, Mursid Raharjo, Onny Setiani
}

\begin{abstract}
Background: Anual Parasite Incidence (API) in West Aceh in 2010 reached 2.6 per 1000 population, then the API in 2011 decreased 1.05 per 1000 population, in 2012 the API decreased 0.9 per 1000 population, API increased to 0.93 per 1000 in 2013.

This research aimed to know the association between environmental, behavioral risk factors and the incidence of malaria in the Working Area of Kuala Bhee Public Health Center in Woyla District.

Methods: It was an observational research using case control design. There were 92 respondents used in this research, consisted of 46 malaria case and 46 controls. Statistical analysis used Chi Square tests, followed by Linear Regresion test.

Result: The results showed that variables that become risk factors of incidence malaria: the presence of livestock pens $(O R=2.673,95 \% C I=1.095-6.521)$, the presence of stagnant water $(O R=4.026,95 \% C I=$ 1.667-9.724), the habit of using mosquito repellent $(O R=3.343,95 \% C I=1.277-8.749)$, and the habit of activity outside the home at night $(O R=4.724,95 \% C I=1.959-11.389)$. The mean density of Anopheles 1.9 fish / person / hour with an average Man Bitting Rate (MBR) 13 tail / night and the average Man Hour Density (MHD) 6.9 fish/person/hour. Not found the presence of sporozoites in all samples of the study

Conclusion: The presence of cattle sheds around the house, the presence of stagnant water around the house which contained larvae, the habit of using mosquito repellent at night time sleep and customs activity outside the home at night has a probability / risk of contracting malaria possibility of $92 \%$.
\end{abstract}

Keywords : malaria, risk factors, environmental, Aceh

\section{PENDAHULUAN}

Penyakit malaria merupakan salah satu penyebab utama terjadinya kematian di banyak negara berkembang terutama pada anak-anak dan ibu hamil sebagai kelompok utama yang mudah terinfeksi. ${ }^{1}$ Malaria merupakan penyakit tropik yang sampai sekarang tersebar luas di daerah tropis maupun subtropis, penyakit yang disebabkan oleh parasit dari genus plasmodium yang ditularkan melalui gigitan nyamuk Anopheles ini, masih ditemukan hampir di seluruh bagian dunia, sedikitnya sekitar 2,3 milyar atau $41 \%$ dari penduduk dunia berisiko terkena malaria. $^{2}$

Penyakit malaria dapat menyerang semua orang dari setiap golongan umur, dari anak - anak sampai orang tua, namun yang memiliki risiko lebih besar terkena malaria adalah anak - anak, ibu hamil, wisatawan - wisatawan yang tidak kebal, pengungsi dan orang - orang yang suka bepergian ke daerah termasuk risiko tinggi malaria. ${ }^{3}$
Berdasarkan World Malaria Report tahun 2014 dilaporkan bahwa 3,2 miliar orang di 97 negara beresiko terinfeksi malaria dan penyakit menular. Sebanyak 1,2 miliar orang berisiko tinggi ( $>1$ dari 1000 berpeluang menderita malaria dalam setahun). Menurut perkiraan, 198 juta kasus malaria terjadi pada tahun 2013 dengan Case Fatality Rate sebesar 584. Kejadian malaria yang terberat adalah di wilayah Afrika, di mana sekitar $90 \%$ dari seluruh kematian yang diakibatkan oleh malaria $78 \%$ di antaranya terjadi pada anak-anak berusia di bawah 5 tahun. $^{4}$

Berdasarkan data dari Direktur Jenderal Pengendalian Penyakit dan Penyehatan Lingkungan (PP dan PL) Kementerian Kesehatan RI tahun 2013 Angka kejadian (positif malaria) mencapai 343.527 kasus dengan Annual Parasite Incidence/API sebesar 1,38 per 1000 penduduk dengan Case Fatality Rate (CFR) sebesar 45. ${ }^{5}$ Insiden Malaria pada tahun 2013 
adalah sebesar 1,9 persen menurun dibanding tahun 2007 (2,9\%), tetapi di Papua Barat mengalami peningkatan tajam jumlah penderita malaria.Prevalensi malaria tahun 2013 adalah 6,0 persen. Lima provinsi dengan insiden dan prevalensi tertinggi adalah Papua $(9,8 \%$ dan $28,6 \%)$, Nusa Tenggara Timur $(6,8 \%$ dan $23,3 \%)$, Papua Barat $(6,7 \%$ dan $19,4 \%)$, Sulawesi Tengah $(5,1 \%$ dan $12,5 \%)$, dan Maluku (3,8\% dan 10,7\%), dari 33 provinsi di Indonesia, 15 provinsi mempunyai prevalensi malaria di atas angka Nasional, sebagian besar berada di Indonesia Timur. Provinsi di JawaBali merupakan daerah dengan prevalensi malaria lebih rendah dibanding provinsi lain. ${ }^{6}$

Kejadian Malaria Klinis di Kabupaten Aceh Barat pada Tahun 2010 Anual Parasit Incidence (API) mencapai 2,6 per 1000 penduduk kemudian API pada tahun 2011 mengalami penurunan sebesar 1,05 per 1000 penduduk dan juga tahun 2012 API mengalami penurunan sebesar 0,9 per 1000 penduduk, kemudian API naik lagi pada tahun 2013 sebesar 0,93 per 1000 penduduk. $^{7}$

Beberapa daerah di Propinsi Aceh dikenal sebagai daerah endemis malaria seperti Sabang, Simeulue, Pulau Aceh, Pulau Banyak untuk kepulauan dan Beutong Ateuh, Padang Tiji, Lampanah, Woyla serta banyak lainnya untuk daratan. Berbeda dengan malaria yang banyak terdapat di daerah kepulauan dan pedalaman. $^{8}$

Penelitian ini bertujuan untuk : a) Mendeskripsikan karakteristik masyarakat berdasarkan jenis kelamin, dan usia pada kelompok kasus dan kontrol, b) Mengukur kepadatan vektor, c) Menganalisis hubungan faktor risiko lingkungan dan perilaku masyarakat dengan kejadian malaria.

\section{MATERI DAN METODE}

Jenis penelitian adalah observasional analitik dengan menggunakan pendekatan case control study. Populasi kasus adalah penduduk yang datang ke puskesmas dengan gejala keluhan demam periodik, nyeri pada persendian dan mual dalam 2 minggu terakhir kemudian diperiksa sediaan darahnya dan ditemukan Plasmodium berdasarkan hasil pemeriksaan darah tepi oleh petugas laboratorium di Puskesmas Kuala Bhee Kecamatan Woyla Kabupaten Aceh Barat dan dinyatakan positif $(+)$ malaria. Kontrol adalah penduduk di wilayah kerja Puskesmas Kuala Bhee Kecamatan Woyla Kabupaten Aceh Barat yang tidak menderita malaria tetapi datang ke Puskesmas dengan keluhan penyakit lain, misalnya luka-luka, batuk dan pilek, kemudian diperiksa sediaan darahnya dan dinyatakan negatif (-) malaria ditandai dengan tidak ditemukannya Plasmodium dalam darah oleh petugas laboratorium.

Besar sampel dihitung dengan menggunakan rumus dari Ariawan dengan jumlah sebanyak 46 sampel untuk kelompok kasus dan 46 untuk kelompok kontrol. ${ }^{9}$ Instrumen penelitian berupa kuesioner, aspirator, paper cup, thermohygrometer dan mikroskop. Penangkapan nyamuk menggunakan metode Human Landing Collection (HLC) pada malam hari mulai dari jam 19.00-01.00 yang dilakukan di rumah kasus dan kontrol. Masing-masing rumah dilakukan oleh 2 orang penangkap. Penangkapann dilakukan di 13 desa di Kecamatan Woyla.

\section{HASIL DAN PEMBAHASAN}

Menurut umur, rerata umur subyek sebesar 38,74 dan standar deviasi sebesar 14,234. Berdasarkan tabel 1 dapat diketahui bahwa kasus malaria terbanyak diderita oleh laki-laki yaitu sebanyak 32 orang $(69,4 \%)$.

Tabel 1 Karakteristik Subjek

\begin{tabular}{lcc}
\hline Karakteristik & Kasus $(\mathrm{n}=46)$ & Kontrol $(\mathrm{n}=46)$ \\
\hline Umur (tahun) : Rerata/ SD & $38,72 \pm 14,234$ & $39,26 \pm 12,468$ \\
Jenis Kelamin & & \\
- Laki-laki & $32(69,4 \%)$ & $22(47,8 \%)$ \\
- Perempuan & $14(30,4 \%)$ & $24(52,2 \%)$ \\
\hline
\end{tabular}

Kepadatan nyamuk Anopheles terendah 1,1 ekor/orang/jam dan tertinggi 4,1 ekor/orang/jam dengan rata-rata 1,9 ekor/orang/jam. Rata-rata Man Bitting Rate (MBR) terendah 6,25 ekor/malam pada titik ke 2 serta tertinggi 13 ekor/malam pada titik ke 4 di kecamatan Woyla.
Rata-rata MHD terendah 0,2 ekor/orang/jam pada 19.00-20.00 dan tertinggi 6.9 ekor/orang/jam pada jam 22.00-23.00. 


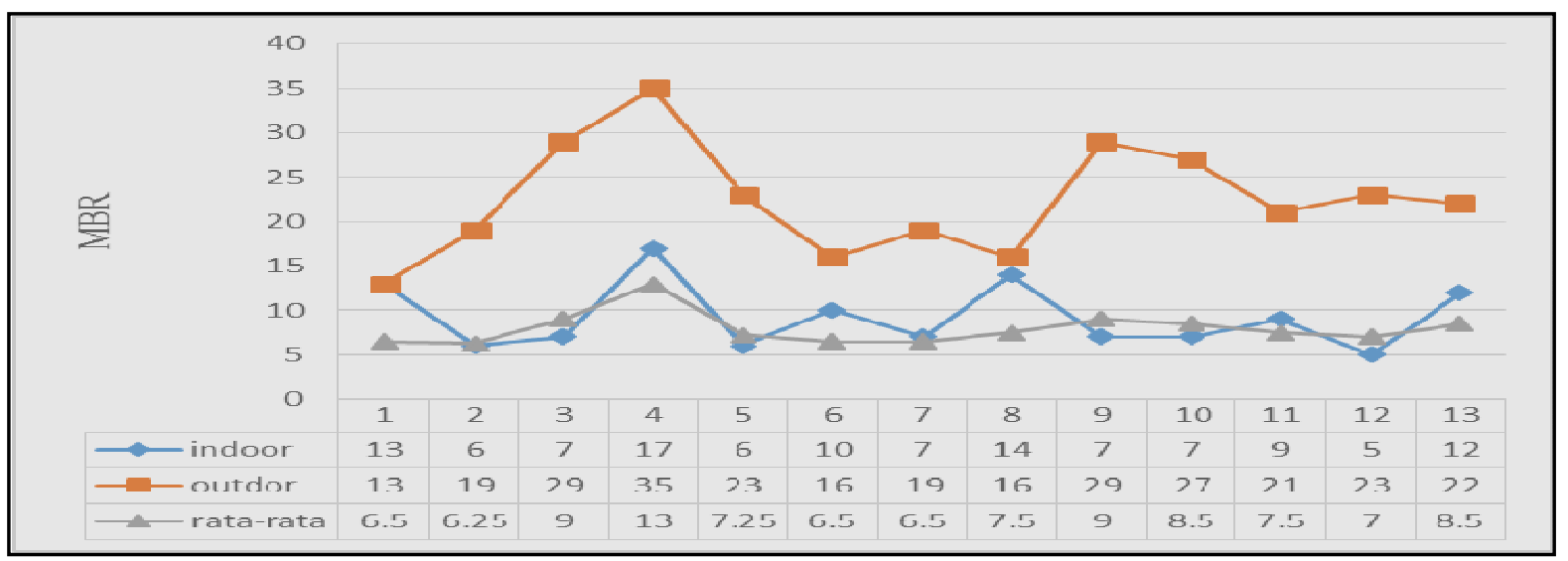

Gambar 1. Grafik Man Bitting Rate (MBR) di dalam dan di luar rumah di wilayah kerja Puskesmas Kuala Bhee Kecamatan woyla

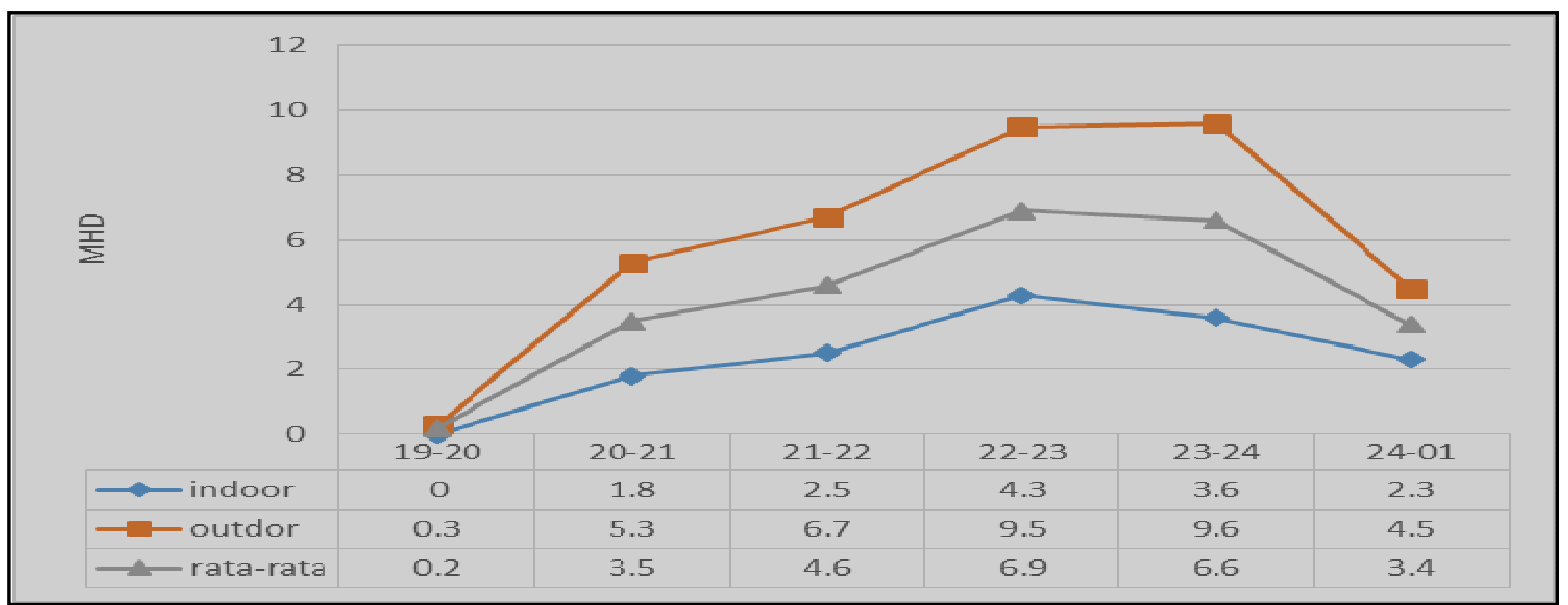

Gambar 2. Grafik Man Hour Density (MHD) di dalam dan di luar rumah berdasarkan jam penangkapan di wilayah kerja Puskesmas Kuala Bhee Kecamatan woyla

Tingginya kepadatan vektor Anopheles disebabkan banyaknya genangan air yang berupa rawa-rawa, sungai, selokan, kolam ikan, kolam kangkung, kolam tempat minum ternak sehingga sangat baik sebagai habitat vektor Anopheles. Kasus kejadian malaria terbanyak terdapat pada Gampong Puloe Ie sebanyak 14 kasus, tingginya kasus ini diakibatkan oleh banyaknya genangan air yang ada di sekitar lingkungan rumah penduduk (rawa-rawa, sungai, selokan, kolam yang terbengkalai) yang dapat menjadi breading place nyamuk Anopheles serta kebiasaan masyarakat beraktivitas di luar rumah pada malam hari.

Analisis bivariat yang dilakukan terhadap faktor risiko malaria untuk menilai hubungan antara masingmasing variabel independen penelitian faktor risiko lingkungan dalam rumah (keberadaan langit-langit, keberadaan kasa ventilasi, kerapatan dinding rumah, suhu dalam rumah), faktor risiko lingkungan luar rumah (keberadaan kandang ternak, keberadaan genangan air, kelembaban), dan faktor perilaku (kebiasaan menggunakan kelambu, kebiasaan menggunakan obat anti nyamuk, kebiasaan beraktifitas di luar rumah pada malam hari) dengan variabel dependen kejadian malaria. Hasil uji bivariat dari variabel independen dengan dependen menggunakan uji Chi Square $\left(\mathrm{X}^{2}\right)$ dengan kemaknaan hubungan secara statistik variabel independen terhadap variabel dependen ditentukan oleh $p$ value $<$ 0,05 dan kekuatan hubungan dengan melihat nilai OR, yang dapat dilihat pada tabel sebagai berikut: 
Tabel 2. Rekapitulasi Hubungan Variabel Fator Risiko dengan Kejadian Malaria di Wilayah Puskesmas Kuala Bhe Kecamatan Woyl.

\begin{tabular}{|c|c|c|c|c|c|}
\hline No & Faktor Risiko & OR & $95 \% \mathrm{CI}$ & Nilai $p$ & Keterangan \\
\hline 1 & Keberadaan Langit-langit & 1,488 & $0,619-3,579$ & 0,505 & Tidak signifikan \\
\hline 2 & Keberadaan kasa pada ventilasi & 1,230 & $0,347-4,355$ & 1,000 & Tidak signifikan \\
\hline 3 & Kerapatan dinding & 1,692 & $0,741-3,861$ & 0,297 & Tidak signifikan \\
\hline 4 & Suhu & 1,131 & $0,427-2,998$ & 1,000 & Tidak signifikan \\
\hline 5 & Keberadaan kandang ternak & 2,673 & $1,095-6,521$ & 0,049 & Signifikan \\
\hline 6 & Keberadaan genangan air & 4,026 & $1,667-9.724$ & 0,003 & Signifikan \\
\hline 7 & Kebiasaan menggunakan kelambu & 1,706 & $0,742-3,921$ & 0,293 & Tidak signifikan \\
\hline 8 & $\begin{array}{l}\text { Kebiasaan menggunakan obat anti } \\
\text { nyamuk }\end{array}$ & 3,343 & $1,277-8,749$ & 0,022 & Signifikan \\
\hline 9 & Kebiasaan beraktifitas di luar rumah & 4,724 & $1,959-11,389$ & 0,001 & Signifikan \\
\hline
\end{tabular}

Keberadaan kandang hewan disekitar rumah dapat menjadi salah satu faktor risiko adanya malaria. Pada kelompok kasus, sebanyak $35(76,1 \%)$ memiliki kandang ternak di sekitar rumah sedangkan pada kelompok kontrol yang memiliki kandang ternak di sekitar rumah sebanyak 25 (54,3\%). Keberadaan kandang ternak dengan kejadian malaria secara statistik ada hubungan yang signifikan. Hal ini didasarkan dari nilai $p=0,049$ dan hasil perhitungan odds ratio (OR) diperoleh nilai sebesar 2,673 menunjukkan penduduk yang mempunyai kandang ternak berisiko terkena malaria 2,673 kali lebih besar dibandingkan dengan penduduk yang tidak mempunyai kandang ternak. Hasil penelitian ini sejalan dengan penelitian Bambang yang menyatakan bahwa lingkungan kandang ternak berpengaruh terhadap peningkatan kepadatan vektor di dalam rumah dan mempengaruhi peningkatan kasus malaria $\left(p=0,001 ;\right.$ OR : 16,98). ${ }^{10}$ Menurut Mayagaya (2015) kandang ternak yang dekat dengan perindukan nyamuk akan mempengaruhi kejadian malaria dan memiliki dampak yang signifikan terhadap keberadaan vektor malaria dan perilaku istirahat nyamuk. $^{11}$

Keberadaan genangan air dengan kejadian malaria secara statistik ada hubungan yang signifikan. Hal ini dapat dilihat dari nilai $p=0,003$ dan hasil perhitungan odds ratio (OR) diperoleh nilai sebesar 4,026 menunjukkan bahwa penduduk yang sekitar rumahnya terdapat air yang tergenang mempunyai risiko terkena malaria 4,026 kali lebih besar dibandingkan dengan orang yang disekitar rumahnya tidak dijumpai genangan air. Di dalam daur hidupnya, nyamuk membutuhkan air, bahkan dengan air yang jumlahnya sangat sedikit nyamuk sudah dapat menggunakannya sebagai tempat perindukan. ${ }^{12}$ Jadi dengan keberadaan genangan air pada jarak tersebut akan mendekatkan manusia dengan vektor nyamuk malaria sehingga risiko terkena malaria pada orang yang tinggal dekat genangan air lebih tinggi dibandingkan orang yang tinggal jauh dari genangan.

Kebiasaan tidak menggunakan obat anti nyamuk dengan kejadian malaria secara statistik ada hubungan yang signifikan. Hal ini dapat dilihat dari nilai $p=$
0,022 dan hasil perhitungan odds ratio (OR) diperoleh nilai sebesar 3,343 menunjukkan penduduk yang tidak menggunakan obat anti nyamuk waktu tidur mempunyai risiko terjadinya malaria 3,343 kali lebih besar dibandingkan dengan orang yang menggunakan obat anti nyamuk. Anti nyamuk merupakan salah satu faktor yang dapat menghindari kontak antara nyamuk dengan manusia. Kebiasaan tidak menggunakan obat anti nyamuk banyak ditemukan pada kasus $(82,6 \%)$, ini dikarenakan banyak responden yang tidak menyukai bau dari obat anti nyamuk tersebut serta kurangnya pengetahuan responden tentang bahaya malaria sehingga menganggap bahwa malaria bukan penyakit yang berbahaya. Menurut Alexander et al (2005) menyatakan bahwa kebiasaan tidak menggunakan obat nyamuk merupakan faktor risiko terjadinya malaria ( $p$ value : 0,012 ; OR :2,02). ${ }^{13}$

Kebiasaan beraktivitas di luar rumah dengan kejadian malaria secara statistik ada hubungan yang signifikan. Hal ini dapat dilihat dari nilai $p=0,001$ dan hasil perhitungan odds ratio (OR) diperoleh nilai sebesar 4,724 menunjukkan penduduk yang mempunyai kebiasaan beraktivitas di luar rumah pada malam hari mempunyai risiko untuk terkena malaria 4,724 kali lebih besar dari orang yang tidak punya kebiasaan beraktivitas di luar rumah pada malam hari. Terdapatnya kasus - kasus malaria pada orang yang mempunyai kebiasaan ke luar rumah dapat dilihat dari proporsi orang yang punya kebiasaan di luar rumah pada malam hari lebih besar pada kelompok kasus $(69,6 \%)$ dibanding kelompok kontrol $(32,6 \%)$.

Hal ini menunjukkan bahwa kebiasaan di luar rumah pada malam hari berisiko terjadinya kontak antara orang sehat dengan nyamuk Anopheles spp. yang membutuhkan darah untuk memenuhi siklus gonotropiknya. Jika nyamuk yang menggigit mengandung sporozoit dalam kelenjar ludahnya, maka peluang orang tertular malaria akan semakin besar. Menurut Mangguang (2015) menyatakan bahwa kebiasaan keluar rumah pada malam hari merupakan faktor risiko kejadian malaria ( $p$ value : 0,029; OR : 4,107). ${ }^{14}$

Variabel yang paling dominan terhadap kejadian malaria, didapat dari analisis bivariat didapat variabel 
terpilih untuk dilanjutkan ke regresi logistik dengan nilai $\mathrm{p}<0,25$ yaitu : keberadaan kandang ternak, keberadaan genangan air, kebiasaan tidak menggunakan obat anti nyamuk dan kebiasaan beraktivitas di luar rumah pada malam hari dapat dilihat pada tabel sebagai berikut:

Tabel 3. Hasil Analisis Regresi Logistik Antara Variabel Potensial dengan Kejadian Malaria di Wilayah Kerja Puskesmas Kuala Bhee Kecamatan Woyla

\begin{tabular}{llcccc}
\hline No & Variabel & B & $p$ value & Exp. $\beta$ & $95 \%$ CI \\
\hline 1 & Keberadaan Kandang ternak & 1,191 & 0,038 & 3,291 & $1,069-10,126$ \\
2 & Keberadaan Genangan air & 1,520 & 0,006 & 4,574 & $1,549-13,506$ \\
3 & $\begin{array}{l}\text { Kebiasaan tidak menggunakan } \\
\text { Obat anti nyamuk }\end{array}$ & 1,507 & 0,021 & 4,515 & $1,258-16,205$ \\
4 & $\begin{array}{l}\text { Kebiasaan Beraktivitas di luar } \\
\text { Rumah }\end{array}$ & 2,058 & 0,000 & 7,384 & $2,541-24,149$ \\
\hline$\quad$ Constanta & $-3,801$ & 0,000 & 0,022 & \\
\hline
\end{tabular}

Berdasarkan hasil analisis multivariat, variabel keberadaan kandang ternak, keberadaan genangan air, kebiasaan menggunakan obat anti nyamuk, kebiasaan beraktivitas di luar rumah pada malam hari secara bersama-sama sebagai faktor risiko untuk kejadian malaria. Hasil analisa multivariat diperoleh variabel yang paling berpengaruh terhadap kejadian malaria adalah kebiasaan beraktivitas di luar rumah pada malam hari.

\section{SIMPULAN}

Berdasarkan hasil penelitian ini dapat disimpulkan faktor lingkungan luar rumah yang berkaitan dengan kejadian malaria di wilayah kerja Puskesmas Kuala Bhee Kecamatan Woyla adalah keberadaan kandang ternak dan keberadaan genangan air. Masing-masing meningkatkan risiko terserang malaria sebesar 2,673 dan 4,026. Dari faktor perilaku/ praktik masyarakat yang berkaitan dengan kejadian malaria adalah kebiasaan tidak menggunakan obat nyamuk yang dapat meningkatkan risiko terserang malaria 3,343 kali dan kebiasaan beraktivitas di luar rumah yang akan meningkatkan risiko tertular malaria sebesar 4,724 kali.

\section{DAFTAR PUSTAKA}

1. Sembel D. Entomologi kedokteran. $1^{\text {st }}$ Ed. Yogyakarta: Andi; 2009.

2. Prabowo A. Malaria mencegah dan mengatasinya. Jakarta: Puspa Swara; 2008.

3. Harijanto P N. Malaria, epidemiologi, patogenesis, manifestasi klinis dan penanganan. Jakarta: Penerbit Buku Kedokteran EGC; 2000.

4. WHO. World Malaria Report. 2014.

5. Depkes RI. Penyakit yang disebabkan oleh nyamuk dan cara Pencegahannya serta Target yang akan dicapai oleh Pemerintah.

6. Badan Penelitian dan Pengembangan. Kesehatan dasar. Jakarta: Kementerian Kesehatan Republik Indonesia; 2013.

7. Dinas Kesehatan Kabupaten Aceh Barat. Profil Kesehatan Kabupaten Aceh Barat. 2013.

8. Dinas Kesehatan Provinsi Aceh. Profil Kesehatan Provinsi Aceh. 2010.

9. Ariawan I, Besar dan metode sampel pada penelitian kesehatan. Jurusan Biostatistik dan
Kependudukan Fakultas Kesehatan Masyarakat. Universitas Indonesia.

10. Bambang $H$, Kandang ternak dan lingkungan kaitannya dengan kepadatan vektor anopheles aconitus di daerah endemis malaria (Tesis). 2005.

11. Valeriana S Mayagaya, Gamba Nkwengulila, Issa N Lyimo, Japheti Kihonda, Hassan Mtambala, Hassan Ngonyani, et al. The impact of livestock on the abundance, resting behaviour and sporozoite rate of malaria vectors in southern Tanzania. Malaria Journal. 2015.

12. Sucipto CD. Vektor penyakit tropis. Yogyakarta: Gosyen Publishing; 2011.

13. Neal Alexander,Mauricio Rodríguez, Ligia Pérez, Juan Carlos Caicedo, Jesús Cruz, Guillermo Prieto, José Antonio Arroyo, et al. Case-control study of mosquito nets against malaria In The Amazon Region Of Colombia. The American Society of Tropical Medicine and Hygiene. 2005.

14. Mangguang. Risk factors of malaria incidence with spasials approaching. Kemas: 2015. 